\title{
BMJ Open Policies supporting informal caregivers across Canada: a scoping review protocol
}

\author{
Akram Khayatzadeh-Mahani, ${ }^{1,2}$ Myles Leslie ${ }^{1,3}$
}

To cite: KhayatzadehMahani A, Leslie M. Policies supporting informal caregivers across Canada: a scoping review protocol. BMJ Open 2018;8:e019220. doi:10.1136/ bmjopen-2017-019220

- Prepublication history and additional material for this paper are available online. To view these files, please visit the journal online (http://dx.doi org/10.1136/bmjopen-2017019220).

Received 18 August 2017 Revised 2 May 2018 Accepted 17 May 2018
Check for updates

${ }^{1}$ School of Public Policy, University of Calgary, Calgary, Alberta, Canada

${ }^{2}$ Health Services Management Research Center, Institute for Futures Studies in Health, Kerman University of Medical Sciences, Kerman, Iran ${ }^{3}$ Department of Community Health Sciences, Cumming School of Medicine, University of Calgary, Calgary, Alberta, Canada

Correspondence to

Dr Myles Leslie;

myles.leslie@ucalgary.ca

\begin{abstract}
Introduction As the population ages, governments worldwide have begun seeking ways to support informal caregiving. In this light, Canada is no exception, but despite the centrality of the informal care strategy in elder care, we know little about the intertwining and overlapping policies that have been implemented to support informal caregivers providing assistance to the elderly, and to fellow citizens with disabilities. This review aims to identify the diversity of Canadian national, provincial and territorial policies supporting informal caregivers. It seeks, from its generalist focus on all informal care, to draw out specific observations and lessons for the elder care policy environment.
\end{abstract}

Methods and analysis Given the vast and multidisciplinary nature of the literature on informal care policy, as well as the paucity of existing knowledge syntheses, we will adopt a scoping review methodology. We will follow the framework developed by Arksey and 0'Malley that entails six stages, including: (1) identifying the research question(s); (2) searching for relevant studies; (3) selecting studies; (4) charting the data; (5) collating, summarising and reporting the results; (6) and conducting consultation exercises. We will conduct these stages iteratively and reflexively, making adjustments and repetitions when appropriate to ensure we have covered the literature as comprehensively as possible. We will pursue an iterative integrated knowledge translation (iKT) strategy engaging our knowledge users through all stages of the review.

Ethics and dissemination By adopting an iKT strategy we will ensure our knowledge users directly contribute to the project's policy relevant publications. Upon completion of the review, we will present the findings at academic conferences, publishing a research report, along with an academic peer-reviewed article. Our intent is to develop an online, free-access evidence repository that catalogues the full range of Canada's English language informal care support policies. Finally, the completed review will allow us to publish a series of policy briefs in collaboration with knowledge users illustrating how to promote and better implement informal care support policies. Our study has received ethics approval from the University of Calgary Conjoint Ethics Board.

\section{INTRODUCTION}

As governments have reduced their involvement in providing institutional long-term

\section{Strengths and limitations of this study}

The review adopts an iterative, integrative approach to knowledge translation by engaging diverse knowledge users in its design, analysis and dissemination.

- This scoping review will inform a full systematic review on the topic.

- The search strategy is broad and includes both peer-reviewed literature (electronic bibliographic databases) and grey literature (both published and unpublished materials that are generally not peer reviewed or indexed in bibliographic databases).

- As French is an official language in a number of Canada's 14 major political jurisdictions, by limiting our search to English language documents we will be excluding some potentially important unilingually French results.

- As this is a scoping review, we do not assess the quality of evidence nor do we rank/grade evidence as is normally performed in a systematic review.

elder care, ${ }^{1-3}$ leveraging informal care for this work has become a key strategy in maintaining healthcare system sustainability worldwide. $^{4-8}$ Informal care refers to the unpaid voluntary care or support provided by family members, friends and neighbours. ${ }^{9}{ }^{10}$ As the population ages, and the cohort aged 65 or over increases, policy attention has shifted to finding ways to support and empower informal groups of helpers and caregivers as part of a strategy to avoid, or delay the institutionalisation of elders ${ }^{68^{11-13}}$ and as part of a trend towards helping people stay in their own homes and communities as they age. ${ }^{14}$ In Canada, for instance, only $2 \%$ of elders, aged 65 and over, receiving publicly funded home care services do not require any additional support from informal carers. The remaining $98 \%$ rely on informal caregivers to provide the help and care necessary for their wellbeing. ${ }^{11}$ Despite being a key policy element, we know little about the strategies, tactics and programmes that have been successful in supporting informal care for the elderly, and in other contexts such as disability. The 
lessons learnt in informal care policy generally may well be valuable in refining specific efforts to support and improve informal care for elders.

Informal caregivers providing care for elders are a specific example of a general trend in the health and social policies of developed nations. We use 'informal caregivers' to refer to groups that arise organically out of their members' interests and needs and that emphasise horizontal, or in-group communication. In contrast, formal caregiving groups are formed out of policy and institutional interests, and emphasise vertical command, control and communications structures. ${ }^{15}$ The concept of an informal care group emerges from the "convoy theory of social support ${ }^{16}$ which posits concentric circles of close-by helpers and even closer caregivers ${ }^{17}$ all of whom bring physical and social resources to delivering care. ${ }^{13} \mathrm{In}$ the Canadian context, the reality of these convoys is that they are far more likely to be dyadic than multimember groups, ${ }^{9}{ }^{18}$ and, as elsewhere in the world, their work falls predominantly to women. ${ }^{19-21}$

Fifty years ago, 'informal care' as either a phrase or concept was unheard of, and the activities of these closeknit groups as they cared for the elderly or persons with a physical or cognitive disability were beyond the attention of policymakers. This began to change as feminist activists and academics through the 1970s brought governmental and societal attention to the fact that women were providing unpaid labour in the majority of households. ${ }^{22}$ This consciousness raising was combined with state-level interests in providing healthcare in the community rather than in institutions. ${ }^{23}{ }^{24}$ It was then only a short step for policymakers to imagine care provision taking place in the community, and being delivered by the community. Through the 1980s and 1990s, 'informal care' became a more widely recognised term, and these groups, oxymoronically, acquired a position in the health and social care policy agenda.

In the UK, the implementation of the Social Security (Invalid Carers Allowance) Regulations of 1976, and the Carers Recognition and Services Act (also known as Carers) of 1995 saw informal caregivers become the specific object of formal policy efforts. The Invalid Carers Allowance, now known as Carer's Allowance, was an income-tested support delivered as a cash benefit to single female carers (not married) and male carers (marital status not specified for them), and represented the first official recognition of informal caregivers in UK law. ${ }^{25}$ The Carers Act gave those who provide 'a substantial amount of care on a regular basis' the right to request an assessment of their needs. The assessment right did not apply to volunteers (paid or unpaid) from organisations providing care. There was, however, no legal duty on the local government to provide such carers with any services or support beyond the assessment of need. ${ }^{24}$ As informal caregivers have become the object of policy attention and knowledge production, and as carers themselves have coalesced around this new identity, variations on, and cognates of the British examples have appeared in the policies of different countries around the world. ${ }^{24}$ 26-28 Thus, putatively 'informal' caregivers in many jurisdictions have come to be integrated into various 'formal' policy, administration or care delivery systems.

Although informal caregivers may operate without direct official institutional support, ${ }^{29}$ they are perhaps best conceptualised as personal, caring inter-relationships among family, friends and relatives that are more or less connected to formal systems of policymaking and care delivery. Indeed, informal caregivers are widely recognised as contributing to the sustainability of formal care systems. ${ }^{30}$ In making these contributions, they extract a broad range of economic ${ }^{3132}$ and time ${ }^{33}$ commitments from informal caregivers with the imputed economic contribution of these caregivers estimated, in Canada, at $\$ 25$ billion per year. ${ }^{34}$ UK estimates based on a replacement cost approach, peg the value of unpaid care provided by informal caregivers working in all contexts at $£ 119$ billon—a number that exceeds the annual cost of running the National Health Service. ${ }^{26}{ }^{35}$ In Canada, and in the specific context of elder care provision, informal caregivers provide between $70 \%$ and $90 \%$ of care for the elderly, with a decline in their activities projected to increase the costs incurred by the formal care system by between $5 \%$ and $35 \% .^{1130}$

While the unpaid, often invisible, ${ }^{36}{ }^{37}$ work of these informal caregivers can be rewarding, ${ }^{38}$ it can also lead to caregiver anxiety ${ }^{39}$ and burnout. ${ }^{41}$ A recent Ontario study shows that nearly a third of families who had been providing informal care for more than 2 years spent on average 20 hours a week. ${ }^{30} 42$ When intensive and sustained, this sort of commitment can limit caregivers' social engagement and participation in the paid labour force, as well as increase the risk of physical and mental health problems. ${ }^{3043}$ A range of studies indicate that the majority of informal caregivers participating in the labour force experience difficulty juggling work and caregiving responsibilities $^{21} 44$ with negative consequences for their peace of mind, ability to sleep, and productiveness and mood at work. ${ }^{45-47}$ Indeed, many caregivers drop out or are forced out of the labour force as they attempt to balance their responsibilities. ${ }^{48}$

The critical need for policies supportive of informal caregivers as they make their significant contributions to society has been recognised. ${ }^{13}$ Policymakers in many developed countries have introduced a range of measures to support informal caregivers such as providing cash benefits, tax credits or legal protections for workers who are also caregivers; and also by improving the integration of informal caregivers into formal system elements such as hospitals, primary care teams, long-term care providers and professional associations. ${ }^{28} 4349$ There has also been an increasing interest, at policy levels, in innovative uses of technology to support caregivers. ${ }^{5051}$ The aim of these various policy supports is to improve informal caregivers' competence in, and capacity to, care ${ }^{52}$ Unfortunately, policy and practice development in the fields of law, regulation, finance, organisational reform and 
technology has been organic rather than systematic, and so the existing literature provides only limited information on the diverse approaches to creating policy that supports informal caregivers or their integration into formal systems.

In this review, we will search for Canadian literature from across disciplines to identify the broad range of policy instruments different provinces and territories have adopted in relation to informal caregivers. In elder care, for example, a range of organisations have come together to ask the federal government to design a 'National Seniors Strategy', with a particular emphasis on supporting caregivers taking the form of enhanced job protection measures, caregiver tax credits and enhanced Canada Pension Plan contribution allowances. ${ }^{53}$ If these are some of the policy options the federal government is pursuing, it is important to understand that Canadian health and social policies are determined and administered across 14 jurisdictions ( 1 central/federal, 10 provincial and 3 territorial). Each jurisdiction has various levels of responsibility and interests, as well as its own political system. These jurisdictional variations have led to the design and implementation of diverse policies in support of informal caregivers. A striking example can be found in policies aimed at promoting and supporting 'self-managed care' (SMC). These have, since the 1970s, become increasingly popular in a range of Canadian jurisdictions. Generally, in an SMC, an earmarked budget is assigned to a recipient of care, who is free to choose services and vendors to meet his or her needs. ${ }^{54}$ Although SMC programmes have been implemented across all 10 provinces, only three provinces-British Columbia, Manitoba and Nova Scotia-permit care recipients to use funds to compensate family caregivers for their labour. ${ }^{55}$ We aim to capture these sorts of cross-jurisdictional variation in what might otherwise appear to be consistent policies. Our aim here is to highlight and understand Canada's variations and to establish a methodological and empirical foundation for a major international comparison. This is to say, the results of the present scoping review will support larger efforts in the future to perform a cross-national comparative review.

In this review, we are going to address the following five objectives: (1) to analyse and synthesise existing Canadian evidence through a comprehensive review of grey and academic literature on policy instruments to support and integrate informal caregivers across Canada; (2) to develop a conceptual framework that classifies diverse informal care policies; (3) to explore different policy objectives behind adopting/developing those policy instruments (eg, well-being, satisfaction, efficiency, effectiveness); (4) to explore potential barriers and facilitators to implementation of diverse policy instruments; and (5) to identify, in conjunction with our knowledge user partners, the approaches, methods and lessons learnt in the broader literature that are applicable to the specific challenges of informal caregivers delivering elder care.

\section{METHODS AND ANALYSIS}

Given the limited nature of existing knowledge on different informal care policies in Canada, the vast and multidisciplinary nature of the literature on informal care (ranging from elder care to disability, and so on), and thus far limited efforts to synthesise existing knowledge, we will use a scoping review methodology. ${ }^{56}$ In a scoping review, the available literature is comprehensively reviewed in order to map the key concepts within a research area and the main sources and types of evidence available. ${ }^{56-58}$ As a scoping review can inform a systematic review, ${ }^{59}{ }^{60}$ it can also assist in determining the value of undertaking a full systematic review on this topic.

The scoping review, with its synthetic approach, is the cornerstone of robust knowledge translation efforts as it transforms a great deal of scientific literature into a reliable form that is readable and relevant to knowledge users. ${ }^{61}{ }^{62}$ The Canadian Institutes of Health Research (CIHR), a federal/national agency that funds health research across Canada, defines a knowledge user as 'an individual who is likely to be able to use the knowledge generated through research to make informed decisions about health policies, programmes and/or practices. ${ }^{, 63} \mathrm{To}$ increase the uptake of our review findings, we will engage diverse knowledge users including content experts, policy and decision makers, practitioners, and informal caregivers in the design, analysis and dissemination of the review. By engaging a wide range of knowledge users in all stages of our review, we hope to coproduce knowledge and evidence that is useful and relevant to those who make real-world decisions and helping them make informed decisions. By adopting this knowledge coproduction approach (also known as integrated knowledge translation (iKT) or participatory research), our knowledge users function as active research partners in generating research from conceptualisation to implementation rather than passive recipients of research or research products. This will enhance our understanding of the knowledge users' context and needs, thereby increasing the policy relevance of our research and enhancing integration of our review findings into policy and practice. It also increases knowledge users' understanding of the research process. ${ }^{64} 65$

We will follow the framework developed by Arksey and O'Malley, ${ }^{56}$ which entails six stages, in our scoping review, as shown in figure 1 . We will treat these stages in an iterative way and will engage with each stage in a reflexive way and repeat steps, where necessary, to make sure that the literature is comprehensively covered.$^{57}$

\section{Stage 1: identifying the research question/s}

As scoping reviews seek to summarise the breadth of evidence, the research questions should be broad. ${ }^{56}$ According to Levac et $a l^{58}$ selecting comprehensive areas of exploration facilitates direction and focus of the study. The overarching question that guides our review is: 'how is informal care being addressed in provincial, territorial, and federal Canadian policies?' Our research 


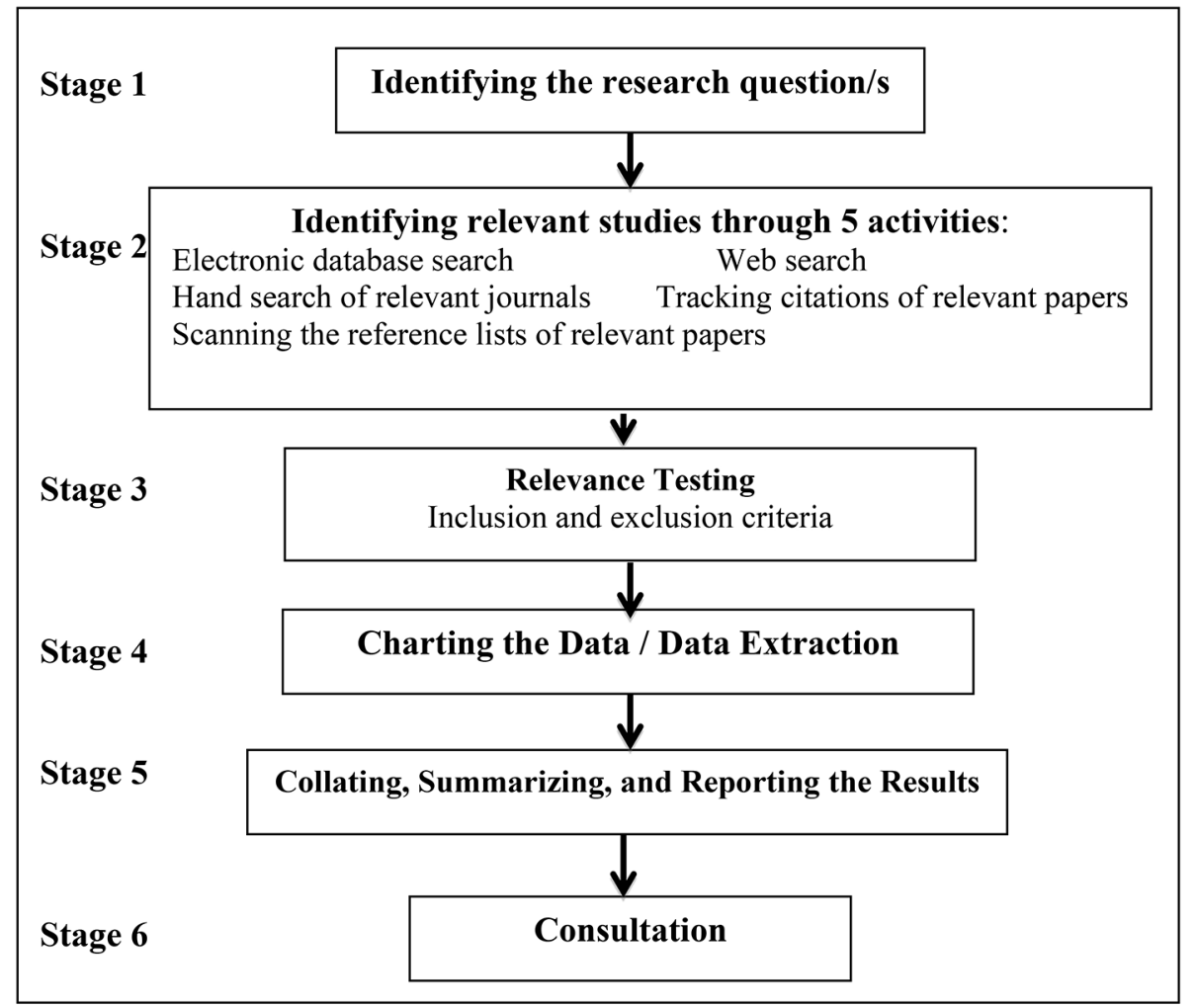

Figure 1 Stages of scoping review.

team initially generated a list of potential research questions based on our experience and initial engagement with the relevant literature. We then began consultations with knowledge users including content experts, policymakers, practitioners and informal caregivers to finalise the research questions. This input from knowledge users will ensure the study's relevance, rigour and comprehensiveness. Specifically, this ongoing engagement aims to improve the uptake of the review results by a broad range of knowledge users. ${ }^{66}$ The following research questions will guide this review:

1. Which informal care policies are being addressed in the Canadian academic and grey literature?

2. What are the policy objectives behind adopting policies to support informal care (eg, well-being, satisfaction, efficiency, effectiveness)?

3. What are the barriers and facilitators of implementation for those policies in support of informal care?

4. What are the policy opportunities and lessons learnt in the broader literature that are applicable to the specific challenges of informal caregivers delivering elder care?

\section{Stage 2: identifying relevant studies}

At this stage, our research team will identify relevant studies and will develop a search strategy, terms to use, sources to be searched, time span and language ${ }^{56}$ In accordance with Arksey and O'Malley's recommendation that 'comprehensiveness is the whole point of scoping the field, ${ }^{56}$ we will employ a very broad search strategy. We will use a search strategy worksheet ${ }^{67}$ (see sample in online supplementary appendix table 1) and will adjust search terms (concepts) based on nuances of each database. Our key concepts will include, but not be limited to: (1) Canada, (2) federal/province/territory, (3) policies, and (4) informal care (see online supplementary appendix table 1 for our detailed search strategy and terms). We will refine our search terms and undertake more sensitive searches of the literature throughout the review process, as necessary.

As part of the broad search strategy, we will undertake the following five activities: electronic database search, web search, hand search of relevant journals, citations of relevant papers and scanning the reference lists of relevant papers.

To perform the electronic database search, we will employ an information scientist (or library scientist). As the research project is multidisciplinary in nature, we will be using diverse electronic databases including: Web of Science, PubMed, MEDLINE via Ovid; Sociological Abstracts; Social Science Citation Index (SSRN); Cumulative Index to Nursing and Allied Health Literature (CINAHL); PsycINFO; and EMBASE via Ovid (excluding MEDLINE) (see the full list of databases in online supplementary appendix table 2). We conducted a preliminary sample search in two databases: MEDLINE and Web of Science. The MEDLINE search strategy produced 1508 records (12 August 2017) while the Web of Science search produced 4083 results (12 August 2017).

Grey literature refers to both published and unpublished materials that are generally not peer reviewed 
or indexed in bibliographic databases. ${ }^{68}$ These include government reports, newsletters and bulletins, technical papers, working papers, theses, data sets and proceedings of the seminars and conferences. Due to the paucity of peer-reviewed academic research in the area of policies in support of informal caregivers, the inclusion of grey literature or non-academic is especially important and valuable. These will also increase the breath, relevance and value of our review findings. For the grey literature, we will search the following websites: Dissertations \& Theses A\& $\mathbf{I}^{\dagger}$ via ProQuest; OpenGrey; ISI Proceedings; Conference Proceedings Citation Index-Social Science and Humanities; Joanna Briggs and ProQuest Dissertations and Theses; PAIS Index-Public Affairs Information Service; Google Scholar; and Google. For specific Canadian grey literature we will search the following databases: Canadian Research Index; Canadian Electronic Library; Canadian Public Policy Index; and LabourSource (formerly Labour Spectrum). Other websites will be identified by the research team and knowledge users.

On completion of these electronic searches, we will conduct a hand search of key journals (eg, Critical Public Health; Health Policy; Health Policy and Planning; Journal of Health Services Research and Policy; Health Services Research; Journal of Aging and Society; Health and Social Care in the Community; Social Policy and Administration; Journal of Aging Studies; The Gerontologist; Journal of Applied Gerontology; BMC Health Services Research; Journal of Aging and Social Policy; The International Journal of Integrated Care; Sociology of Health and Illness; Journal of Aging and Health; and key gerontological nursing journals) which will be identified by the research team and content experts. Citations of relevant papers will be also tracked. Finally, the reference lists of relevant papers will also be searched in order to find papers not identified in the initial search. All retrieved searches will be imported into Endnote in which the duplicate references will be identified and discarded. Since selected electronic databases to download citations and referencing are often inconsistent in their content and formatting, we anticipate a manual search for duplicates. ${ }^{66}$

\section{Stage 3: relevance testing}

In order to increase the rigour of our review, we will adopt a team approach ${ }^{58}$ to determine which studies/materials to include. At the beginning of the scoping review, the team will discuss and finalise the inclusion and exclusion criteria. The research team has initially decided to include any papers published since 1970 as informal caregivers became the specific object of formal policy efforts at this time. While our interest is in policies supporting informal care as they deliver elder care, this is an exploratory study, and as such we will not limit our search strategy to elder care. Rather, in an effort to achieve a breadth of understanding, and to facilitate comparative synthesis of opportunities and lessons learnt we will include disability to target a broader range of informal care policy literature. We have also decided on the following inclusion criteria but these may be revised and refined following further engagement with our knowledge user partners.

\section{Initial inclusion criteria}

- Academic and grey literature related to Canada only.

- Papers or documents that discuss policies to support informal caregivers (in the areas of elder care and disability).

- Published or unpublished primary studies (quantitative, qualitative or mixed-methods studies), theses/ dissertations, conference papers, theoretical discussions and grey literature.

Initial exclusion criteria

- Papers or documents published before 1970.

- Papers or documents not published in English.

- Book reviews.

- Commentary and editorial papers.

- Non-Canadian materials (academic and grey literature).

As recommended by Levac et $a l^{58}$ our reviewers will meet at the start, middle and end of the abstract review process in order to discuss any challenges or ambiguities related to study selection and to refine, where necessary, the search strategy. We will develop, in consultation with our knowledge user partners, a screening tool, to determine the relevance of papers to informal care policies and also to code the type of data retrieved (eg, reviews, empirical data, theoretical discussion, policy brief, government documents, web content, conference paper). We will recruit two graduate students (Master of Public Policy) who have received training in the scoping review process to screen the titles, abstracts/summaries or executive summaries that are returned by the search. These reviewers will classify records as 'potentially relevant' or 'exclude'. When the relevance of a publication is in doubt, the full text will be retrieved. To mitigate bias in the selection process, two members of the research team will independently review $1 \%$ of the abstracts/summaries and compare their results with the graduate students' results. Our research questions may require some refinement at this stage to ensure the review's feasibility and relevance.

Next, the graduate student reviewers will independently retrieve and review all full texts coded as 'potentially relevant' as part of considering them for inclusion. In the case of disagreements between the two reviewers on inclusion, the other team members will be consulted to make the final decision. During this stage, the research team will organise monthly meetings/teleconferences to discuss progress, findings, challenges and uncertainties related to study selection.

\section{Stage 4: charting the data}

At this stage, we will extract data from the included studies, using a deductively generated coding tree and importing the data into NVivo V.10 for data analysis. Our research team will collectively develop the data-charting form (or 
extraction form), using Framework Matrix capability in Nvivo, ${ }^{69}$ in order to decide on extract variables that best help answer our research questions. The extraction form will be derived from our research questions and also from the best relevant papers. We will treat charting as an iterative process in which we will constantly update the data-charting form as the analysis proceeds, similar to the process used in inductive coding in qualitative data analysis. The two graduate students with two members of the research team will independently extract data, using a data-charting form, from the first five studies and check if their data extraction approach is consistent with the research questions. The graduate students will then independently continue extracting data and the research lead will double check the extracted data to ensure accuracy and completeness.

Our potential data extracted will include: Canadian location: federal/province/territory, author/s or institution/s or organisation/s, publication title, publication year, research question or study purpose, policy objectives (eg, well-being, satisfaction, efficiency, effectiveness) and barriers/facilitators to implementation of policies. This list of extracted data will be modified as the research team becomes more familiar with the literature.

\section{Stage 5: collating, summarising and reporting the results}

This stage is generally the most extensive phase of a scoping review. Once we gather/extract all data, we will establish a working group to meaningfully interpret the data. With the research questions in mind, the two graduate students will quantify the extracted data and produce a descriptive summary of the included materials (eg, for journal articles we will extract overall number of studies included, types of study design, years of publication, study population and provinces/territories where studies were conducted).

As scoping reviews are not a short summary of journal articles and grey literature, the analytical synthesis of extracted data is critical. As such, we will conduct a constant comparative analysis using NVivo V.10 in order to organise our data into overarching categories. Using constant comparison analysis allows: comparisons to be made across concepts, similarities, differences, and gaps to be identified, and a conceptual framework to emerge. During the synthesis phase, we will systematically integrate the extracted data and will develop a taxonomy of informal care policies. We will develop a conceptual framework with the following potential key elements for classification which will also be the starting point for our coding nodes: the policy instruments; policy objectives (eg, well-being, satisfaction, efficiency, effectiveness); and barriers and facilitators. We will seek the views of our knowledge users at this phase via email, teleconference or web conference to allow their inputs in reviewing the findings, before providing policy recommendations. ${ }^{56}$

\section{Stage 6: consultation}

Consultation enhances the methodological rigour of the review and should be a compulsory stage in scoping reviews. ${ }^{58}$ In our scoping review, we will involve knowledge users at all stages of the review. By doing so, we will move beyond knowledge translation towards an iterative iKT. ${ }^{70}$ We will seek knowledge users' input to further refine the review questions; to add a higher level of meaning, content and expertise to our review preliminary findings; to tailor our review findings to the knowledge users' needs (in terms of policy practice); and to make our review findings more applicable. We will engage knowledge users in the first stages of the review via email and teleconference. We will hold a workshop/policy roundtable with knowledge users to have their input for developing the comprehensive conceptual framework that classifies informal care policies.

\section{PATIENT AND PUBLIC INVOLVEMENT}

CIHR Strategy for Patient Outcome Research provides a broad definition of 'patient' that includes caregivers and family members. In our research, we will recruit informal caregivers, from community organisations such as IMAGINE Citizens (an independent group of Alberta citizens who participate in patient-oriented research) as a proxy for the broad term of 'patient'. In developing the scoping review protocol, our research team initially generated a list of potential research questions based on our experience and initial engagement with the relevant literature. We then began consultations with knowledge users including informal caregivers, via email and teleconference, to finalise the research questions. We will engage informal caregivers throughout the entire cycle of our research. We will seek their input for a number of reasons, among others, to further refine our review questions; to tailor our review findings to their needs; to add a higher level of meaning, content and expertise to our review preliminary findings; and to make our review findings more applicable. We will hold a workshop/policy roundtable with knowledge users, including informal caregivers, to have their input for developing the comprehensive conceptual framework that classifies informal care policies.

As our study engages a wide range of knowledge users and stakeholders, including informal caregivers, we will disseminate the results of our review via diverse means. For the specific audience of informal caregivers our dissemination strategies include: blogs that intersect academic and popular internet dissemination; a short (3-4 min) YouTube (or series of YouTube videos) discussing policy implications of the findings; a webinar in collaboration with our knowledge users; and media interviews to disseminate findings and support the uptake of results.

\section{ETHICS AND DISSEMINATION}

This scoping review aims to synthesise the existing Canadian evidence about informal care policies to enhance understanding about these policies and to extrapolate 
policy instruments that may be particularly relevant for elderly care. The main outputs of this knowledge synthesis will be (1) a conceptual framework that classifies policy instruments that support informal care or integrate them into formal systems of care, and (2) potential barriers and facilitators for implementing those policies.

We will disseminate the results of our review via diverse means, publishing and presenting in academic fora. Our intention is to develop a conceptual framework that classifies informal care policies, and use this framework to organise an online, free-of-charge, evidence repository. We will further publish a series of policy briefs to be developed collaboratively with knowledge users about how to promote and better implement informal care policies. Other means of disseminating our review results include blogs that intersect academic and popular internet dissemination; a short (3-4 min) YouTube (or series of YouTube videos) discussing policy implications of the findings; a webinar in collaboration with our knowledge users; and media interviews to disseminate findings and support the uptake of results. We will pursue an iKT strategy as our knowledge users are closely engaged throughout the entire research cycle, and directly contribute to the policy relevant publications of the project (see online supplementary appendix table 3 for full list of dissemination tools for different target audiences).

Contributors AKM and ML together conceived the review approach. AKM wrote the first draft of the manuscript. ML critically reviewed and revised the manuscript. Both AKM and ML read and approved the final version of the manuscript.

Funding This research received no specific grant from any funding agency in the public, commercial or not-for-profit sectors.

Competing interests None declared.

Patient consent Not required.

Ethics approval The University of Calgary Conjoint Ethics Board.

Provenance and peer review Not commissioned; externally peer reviewed.

Open access This is an open access article distributed in accordance with the Creative Commons Attribution Non Commercial (CC BY-NC 4.0) license, which permits others to distribute, remix, adapt, build upon this work non-commercially, and license their derivative works on different terms, provided the original work is properly cited and the use is non-commercial. See: http://creativecommons.org/ licenses/by-nc/4.0/

(c) Article author(s) (or their employer(s) unless otherwise stated in the text of the article) 2018. All rights reserved. No commercial use is permitted unless otherwise expressly granted.

\section{REFERENCES}

1. Aronson J, Neysmith SM. The Retreat of the State and Long-Term Care Provision: Implications for Frail Elderly People, Unpaid Family Carers and Paid Home Care Workers. Studies in Political Economy 1997;53:37-66.

2. Aronson J, Neysmith SM. Obscuring the costs of home care: restructuring at work. Work, Employment and Society 2006;20:27-45.

3. Daly T. Out of place: mediating health and social care in Ontario's long-term care sector. Can J Aging 2007;26 Suppl 1(S1):63-75.

4. Carstairs S, Keon W. Special senate committee on aging: final report. Ottawa, ON: Government of Canada, 2009.

5. Grunfeld E, Glossop R, McDowell I, et al. Caring for elderly people at home: the consequences to caregivers. CMAJ 1997;157:1101-5.

6. Criel B, Vanlerberghe V, De Koker B, et al. Informal home care for elderly in Belgium: a study on the features and challenges of informal care at local level. Community Ment Health J 2014;50:848-53.
7. Singer GHS, Biegel DE, Ethridge BL. Trends Impacting Public Policy Support for Caregiving Families. J Fam Soc Work 2010;13:191-207.

8. Levine C, Halper D, Peist A, et al. Bridging troubled waters: family caregivers, transitions, and long-term care. Health Aff 2010;29:116-24.

9. Fast J, Keating N, Otfinowski P, et al. Characteristics of family/friend care networks of frail seniors. Can J Aging 2004;23:5-19.

10. Willemse E, Anthierens S, Farfan-Portet Ml, et al. Do informal caregivers for elderly in the community use support measures? A qualitative study in five European countries. BMC Health Serv Res 2016;16:270.

11. Information ClfH. Supporting Informal Caregivers - The Heart of Home Care. In. Ottawa, ON: CIHI, 2010.

12. Forum MH. Improving Support for Unpaid Caregivers in Ontario: Panel Summary. In. Hamilton, ON: McMaster University, 2014.

13. Barrett $P$, Hale B, Butler M. Informal care in context: an expression of social relationships. Family care and social capital: transitions in informal care. Springer: Springer, 2014:17-34.

14. De Aguiar CH, Fateminasab R, Frazelle CG, et al, 2016. The networked, robotic home+ furniture suite: a distributed, assistive technology facilitating aging in place. IEEE International Conference on 2016. Automation Science and Engineering (CASE).

15. Simon $\mathrm{H}$, Behavior A. How organizations can be understood in terms of decision processes. New York: Free Press, 1974.

16. Antonucci TC, Ajrouch KJ, Birditt KS. The convoy model: explaining social relations from a multidisciplinary perspective. Gerontologist 2014;54:82-92

17. Sims-Gould J, Martin-Matthews A. Family caregiving or caregiving alone: who helps the helper? Can J Aging 2007;26(S1):27-45.

18. Fast J. Caregiving for Older Adults with Disabilities. Montreal, QC: IRPP, 2015.

19. Fast J, Duncan K, Dunlop C, et al. Policy Brief No. 2 - Gender differences in family/friend caregiving in Canada. Ottawa, ON: Government of Canada, 2011

20. Gallicchio L, Siddiqi N, Langenberg P, et al. Gender differences in burden and depression among informal caregivers of demented elders in the community. Int J Geriatr Psychiatry 2002;17:154-63.

21. Andersson S, Erlingsson C, Magnusson L, et al. Information and communication technology-mediated support for working carers of older family members: an integrative literature review. Int $J$ Care Caring 2017;1:247-73.

22. Himmelweit S, Plomien A. Feminist perspectives on care: theory, practice and policy. The Sage Handbook of Feminist Theory. London: Sage, 2014:446-65.

23. Milne A, Larkin M. Knowledge generation about care-giving in the UK: a critical review of research paradigms. Health Soc Care Community 2015;23:4-13.

24. Heaton J. The gaze and visibility of the carer: a Foucauldian analysis of the discourse of informal care. Sociology of Health and IIIness 1999;21:759-77.

25. DeMello S, Furseth PI. Innovation and Culture in Public Services: The case of independent living. Edward Elgar Publishing 2016.

26. Schneider $U$, Sundström G, Johannson L, et al. Policies to support informal care. Long-term care reforms in OECD countries 2015:219-46.

27. Einolf CJ, Prouteau L, Nezhina T, et al. Informal, Unorganized Volunteering. The Palgrave Handbook of Volunteering, Civic Participation, and Nonprofit Associations: Springer, 2016:223-41.

28. Casanova G, Lamura G, Principi A. Valuing and Integrating Informal Care as a Core Component of Long-Term Care for Older People: A Comparison of Recent Developments in Italy and Spain. J Aging Soc Policy 2017;29:1-17.

29. Lum J. Informal Caregiving Focus Backgrounder. Toronto, ON: Canadian Research Network for Care in the Community, 2011.

30. Peckham A, Williams AP, Neysmith S. Balancing formal and informal care for older persons: how case managers respond. Can J Aging 2014;33:123-36.

31. Keating NC, Fast JE, Lero DS, et al. A taxonomy of the economic costs of family care to adults. The Journal of the Economics of Ageing 2014;3:11-20.

32. Stadnyck R, Fletcher S, Eales J, et al; Employed Family/Friend Caregivers to Adults with Disabilities: The Impact of Public Policies on Caregivers' Costs. Universtiy of Alberta: Department of Human Ecology, 2008.

33. Wimo A, Winblad B, Jönsson L. An estimate of the total worldwide societal costs of dementia in 2005. Alzheimers Dement 2007;3:81-91.

34. Hollander MJ, Liu G, Chappell NL. Who cares and how much? The imputed economic contribution to the Canadian healthcare system of middle-aged and older unpaid caregivers providing care to the elderly. Healthc Q 2009;12:42-9. 
35. Buckner L, Yeandle S. Valuing Carers 2011 Calculating the value of carers' support [Internet]. Leeds, UK. $2011 \mathrm{http}$.circleleedsacuk/ files/2012/08/110512-circle-carers-uk-valuing-carers pdf.

36. Ansello EF, Rosenthal C. Editorial: Hidden costs and invisible contributions in family caregiving: an introduction. Can J Aging 2007;26:1-6.

37. Grant G. Invisible contributions in families with children and adults with intellectual disabilities. Can J Aging 2007;26(S1):15-26.

38. Cohen CA, Colantonio A, Vernich L. Positive aspects of caregiving: rounding out the caregiver experience. Int $J$ Geriatr Psychiatry 2002;17:184-8.

39. Lopez-Hartmann M, Wens J, Verhoeven V, et al. The effect of caregiver support interventions for informal caregivers of communitydwelling frail elderly: a systematic review. Int $J$ Integr Care 2012:12:e133.

40. Schulz R, Martire LM. Family caregiving of persons with dementia: prevalence, health effects, and support strategies. Am J Geriatr Psychiatry 2004;12:240-9.

41. Fast J, Keating N, Yacshyn A. "I wish that I could just have a break": Consequences of supporting adults with disabilities. University of Alberta: Department of Human Ecology, 2008.

42. Turcotte M. Family caregiving: What are the consequences? 2013.

43. Keefe J, Guberman N, Fancey P, et al. 19-Caregiver Assessment: An Essential Component of Continuing Care Policy. Population Change and Lifecourse Strategic Knowledge Cluster Research/Policy Brief 2016;1:7.

44. Reed C, Belger M, Dell'agnello G, et al. Caregiver Burden in Alzheimer's Disease: Differential Associations in Adult-Child and Spousal Caregivers in the GERAS Observational Study. Dement Geriatr Cogn Dis Extra 2014;4:51-64.

45. Jarrold K, Yeandle S. A weight off my mind: Exploring the impact and potential benefits of telecare for unpaid carers in Scotland. Glasgow, Scotland: Carers Scotland and the University of Leeds, 2009.

46. Mahoney DM, Mutschler PH, Tarlow B, et al. Real world implementation lessons and outcomes from the Worker Interactive Networking (WIN) project: workplace-based online caregiver support and remote monitoring of elders at home. Telemed J E Health 2008;14:224-34.

47. Reder S, Ambler G, Philipose M, et al; Technology and Long-term Care (TLC): A pilot evaluation of remote monitoring of elders, 2010.

48. Lorig K, Thompson-Gallagher D, Traylor L, et al. Building Better Caregivers. Journal of Applied Gerontology 2012;31:423-37.

49. Rajnovich B, Keefe J. Supporting caregivers of dependent adults in the 21st century, 2005.

50. AGE-WELL. Home Page. 2017 http://agewell-nce.ca/ (accessed 10 Aug 2017).

51. ESoDlfAaH A. Blueprint for a digital transformation of health and care in an ageing society. In 2016.

52. Stoltz P, Andersson EP, Willman A. Support in nursing--an evolutionary concept analysis. Int J Nurs Stud 2007:44:1478-89.
53. Strategy NS. Ensuring that the family and friends of older Canadians who provide unpaid care for their loved ones are acknowledged and supported. 2017 http://nationalseniorsstrategy.ca/the-four-pillars/ pillar-4/.

54. Spalding K, Watkins JR, Williams AP. Self Managed Care Programs in Canada: A Report to Health Canada, 2006.

55. British Columbia Law Institute. Care/Work: Law Reform to Support Family Caregivers to Balance Paid Work and Unpaid Caregiving: British Columbia Law Institute, 2010.

56. Arksey H, O'Malley L. Scoping studies: towards a methodological framework. Int J Soc Res Methodol 2005;8:19-32.

57. Daudt HM, van Mossel C, Scott SJ. Enhancing the scoping study methodology: a large, inter-professional team's experience with Arksey and O'Malley's framework. BMC Med Res Methodol 2013;13:48

58. Levac D, Colquhoun H, O'Brien KK. Scoping studies: advancing the methodology. Implement Sci 2010;5:69.

59. Langlois EV, Ranson MK, Bärnighausen T, et al. Advancing the field of health systems research synthesis. Syst Rev 2015;4:90.

60. Armstrong R, Hall BJ, Doyle J, et al. 'Scoping the scope' of a cochrane review. J Public Health 2011;33:147-50.

61. Harvey G. The many meanings of evidence: implications for the translational science agenda in healthcare. Int $J$ Health Policy Manag 2013:1:187-8.

62. Salbach NM. Knowledge translation, evidence-based practice, and you. Physiother Can 2010;62:293-4.

63. Canadian Institutes of Health Research. About knowledge translation. 2018 http://www.cihr-irsc.gc.ca/e/29418.html (accessed 28 Feb 2018).

64. Rycroft-Malone J, Burton CR, Bucknall T, et al. Collaboration and coproduction of knowledge in healthcare: opportunities and challenges. Int J Health Policy Manag 2016;5:221-3.

65. Kothari A, McCutcheon C, Graham ID. Defining Integrated Knowledge Translation and Moving Forward: A Response to Recent Commentaries. Int J Health Policy Manag 2017;6:299-300.

66. Valaitis R, Martin-Misener R, Wong ST, et al. Methods, strategies and technologies used to conduct a scoping literature review of collaboration between primary care and public health. Prim Health Care Res Dev 2012;13:219-36.

67. Riedling AM. Learning To Learn: A Guide to Becoming Information Literate: ERIC, 2002.

68. Tillett S, Newbold E. Grey literature at The British Library: revealing a hidden resource. Interlending \& Document Supply 2006;34:70-3.

69. Sweet L. Using NVivo and EndNote For Literature Reviews. 2014 http://www.flinders.edu.au/staff-development-files/computer/NVivo_ Endnote_Lit_review.pdf (accessed 20 Feb 2018).

70. Grimshaw J. A Knowledge Synthesis Chapter: Canadian Institutes of Health Research, 2015. 